\title{
The predictive value of galectin-1 and vascular mimicry in the prognostic evaluation of patients with rectal cancer
}

\author{
Haihua Zhou ${ }^{1,2 \#}$, Degeng Zhang ${ }^{3 \#}$, Minyan Yang ${ }^{4}$, Xiaolan You ${ }^{5}$, Qi Zhang ${ }^{6}$, Xiaoyang Fu ${ }^{7}$, Daorong Wang ${ }^{8}$ \\ ${ }^{1}$ Medical College of Yangzhou University, Yangzhou, China; ${ }^{2}$ Department of Anorectal Surgery, Affiliated Hospital of Medical College of Yangzhou \\ University (Taizhou People's Hospital), Taizhou, China; ${ }^{3}$ Department of Hematology Oncology, The Affiliated Hospital of Yangzhou University \\ School of Medicine (Jiangsu Taizhou People's Hospital), Taizhou, China; ${ }^{4}$ Department of Reproductive center, The Affiliated Hospital of Yangzhou \\ University School of Medicine (Jiangsu Taizhou People's Hospital), Taizhou, China; ${ }^{5}$ Department of Gastrointestinal Surgery, The Affiliated Hospital \\ of Yangzhou University School of Medicine (Jiangsu Taizhou People's Hospital), Taizhou, China; ${ }^{6}$ Department of Gastrointestinal Surgery, Subei \\ Hospital Affiliated to Yangzhou University, Yangzhou, China; ${ }^{7}$ Department of Central laboratory, The Affiliated Hospital of Yangzhou University \\ School of Medicine (Jiangsu Taizhou People's Hospital), Taizhou, China; ${ }^{8}$ Department of Gastrointestinal Surgery, Subei Hospital Affiliated to \\ Yangzhou University (Jiangsu Subei People’s Hospital), Yangzhou University-Yangzhou General Surgery Institute, Yangzhou, China \\ Contributions: (I) Conception and design: H Zhou, D Zhang; (II) Administrative support: None; (III) Provision of study materials or patients: Q \\ Zhang, D Wang; (IV) Collection and assembly of data: M Yang, X You; (V) Data analysis and interpretation: X Fu; (VI) Manuscript writing: All \\ authors; (VII) Final approval of manuscript: All authors. \\ \#These authors contributed equally to this work. \\ Correspondence to: Daorong Wang. Department of Gastrointestinal Surgery, Subei Hospital Affiliated to Yangzhou University (Jiangsu Subei People's \\ Hospital), Yangzhou University-Yangzhou General Surgery Institute, Yangzhou, China. Email: wdaorong666@sina.com.
}

Background: This study aims to investigate the expression of galectin-1 and vascular mimicry (VM) in rectal cancer tissues, and to assess their predictive value in the prognostic evaluation of patients with rectal cancer.

Methods: Immunohistochemistry (IHC) and CD34-periodic acid solution (PAS) double staining were used to detect galectin-1 expression and the formation of VM in rectal cancer tissues from 94 patients with stage I-III rectal cancer and their corresponding paracancerous tissues. We also analyzed the relationship between the expression of galectin-1, VM, various clinicopathological parameters, and the prognosis of rectal cancer patients, as well as their influence on the overall survival (OS) of rectal cancer patients.

Results: Among the 94 tissue specimens from rectal cancer patients, 43 had positive expression of galectin-1 and 19 had positive expression of VM. There was a positive correlation between VM and galectin-1 expression in rectal cancer tissue. Galectin-1 expression in rectal cancer tissue and the formation of VM were related to tumor differentiation, staging, lymph node metastasis, and intravascular tumor thrombus $(\mathrm{P}<0.05)$. Kaplan-Meier analysis showed that the OS time of rectal cancer patients in the galectin-1 positive expression group was shorter than the galectin-1 negative expression patients, and the difference between the 2 groups was statistically significant $(\mathrm{P}=0.003)$. The OS time of patients with rectal cancer in the VM positive expression group was shorter than the VM negative expression group, and the difference between the two groups was statistically significant $(\mathrm{P}<0.001)$. The OS time of the galectin-1 and VM negative expression group was $57.33 \pm 1.13$ months, and the OS time of the galectin-1 and VM positive expression group was $43.21 \pm 3.97$ months, while the OS time of the galectin-1 positive expression and VM negative expression group was $55.42 \pm 2.23$ months, and the difference between the three groups was statistically significant $(\mathrm{P}<0.001)$. Multi-factor analysis results indicated that invasion depth and VM expression were independent risk factors that affected the OS of patients with rectal cancer.

Conclusions: Galectin-1 and VM expression in rectal cancer tissues may predict poor prognosis in patients after radical surgery. Galectin-1 and VM may therefore become potential new targets for rectal cancer treatment. 
Keywords: Galectin-1; vascular mimicry (VM); immunohistochemistry; rectal cancer; prognosis

Submitted Dec 15, 2020. Accepted for publication Mar 12, 2021.

doi: $10.21037 /$ tcr-21-121

View this article at: http://dx.doi.org/10.21037/tcr-21-121

\section{Introduction}

In China, compared to all malignant tumors, the incidence and mortality of rectal cancer are high (1). In recent years, anti-vascular endothelial growth factor drug therapy has been considered to be an effective treatment after tumor chemotherapy resistance (2). However, the clinical efficacy of such anti-vascular endothelial factor growth drugs has not been consistent. The reason is that in addition to endothelial cells relying on blood vessels and tumor tissues, there are also mimic blood vessels that do not rely on endothelial cells. Some studies have found that anti-angiogenic therapy reduces blood vessel density, promotes the generation of hypoxia-inducible factors, and thereby induces the formation of vascular mimicry (VM) $(3,4)$. VM refers to the formation of highly malignant tumor cells that simulate vascular endothelial cells through self-deformation and interact with extracellular matrix to simulate vascular wall structure. A system of ducts that transport blood (plasma, red blood cells) to reshape the tumor's microcirculation and connect with host blood vessels to provide the tumor with a blood supply. VM has been found in many solid tumors and is an important supplement to the classical blood supply of tumors. It can provide more blood supply and nutrients to tumor tissues and promote tumor growth. VM has the following characteristics: the vascular tubes formed are arranged in clusters or patterns; there was no vascular endothelial cell liner covering the tubes, and CD31/CD34 staining was negative in immunohistochemistry; it was surrounded by a lot of extracellular matrix such as laminin, fibritin and collagen, and it was positive for Perioacid-Schiff (PAS) staining $(5,6)$. Due to the lack of endothelial cells, the VM structure is only a tubular structure surrounded by mucopolysaccharide components, which is convenient for tumor cells to invade. In addition, VM connects with endothelium-dependent blood vessels and is an important pathway for tumor cells to enter the blood circulation (7). Studies have shown that the formation of VM indicates the high aggressiveness of tumor cells, is closely related to the recurrence and progression of tumors, and suggests poor prognosis of tumors (8). Studies have found that in gastric cancer tissue, the expression of galectin-1 promotes the formation of gastric cancer VM, and suggests a poor prognosis for gastric cancer (9-11). There have been no relevant reports on VM generation in rectal cancer and its effect on prognosis of rectal cancer patients, nor has there been any relevant reports on whether Galectin-1, which regulates tumor endothelial cell-dependent angiogenesis, can regulate VM generation in rectal cancer. This study aims to investigate whether there is a correlation between VM and galectin-1 expression in rectal cancer tissues, analyze their predictive value in the prognostic evaluation of rectal cancer, and provide clinical indicators for the choice of postoperative treatment for patients with rectal cancer. We present the following article in accordance with the REMARK reporting checklist (available at http://dx.doi. org/10.21037/tcr-21-121).

\section{Methods}

\section{Clinical data}

The paraffin-embedded specimens of 94 patients who underwent rectal cancer surgery in the gastrointestinal surgery department of our hospital from January 2011 to December 2014 were selected from the gastrointestinal tumor biobank of our hospital. All selected patients received standard total mesorectal excision (TME) of rectal cancer, none of them had received neoadjuvant radiochemotherapy or biological therapy before surgery, no distant metastasis or other malignant tumors were found before surgery, and none of the patients had serious underlying diseases. According to the postoperative pathological results, patients with chemotherapy indications started XELOX (capecitabine and oxaliplatin) chemotherapy 4 weeks after the operation, and the total course of treatment was 6 months. The followup began after the patient was discharged from the hospital and ended in December 2019, with a clinical follow-up of 5 years. Table 1 shows the detailed clinical and pathological data of the selected patients.

The study was conducted in accordance with the Declaration of Helsinki (as revised in 2013). The study was approved by Affiliated Hospital of Medical College of Yangzhou University (NO. TZRY-EC-18-012). All subjects 
Table 1 The relationship between galectin-1, VM, and clinicopathological characteristics after immunohistochemistry and CD34-PAS double staining of paraffin sections from 94 patients with rectal cancer

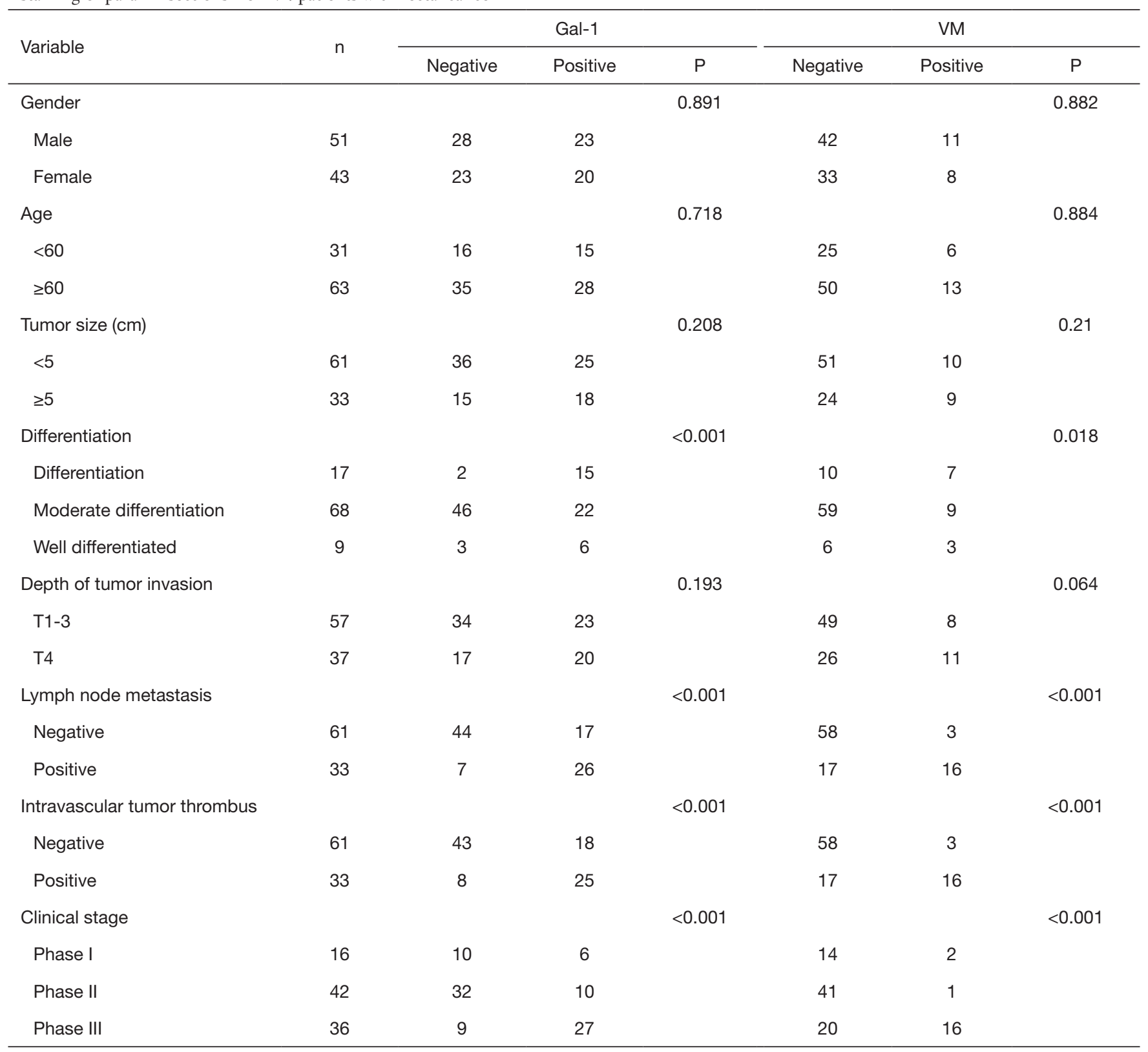

VM, vascular mimicry; PAS, periodic acid solution; Gal-1, galectin-1.

were informed and signed the informed consent.

\section{Main instruments and reagents}

LEICA automatic tissue dehydration machine was purchased from Leica (Germany, ASP300); Passage Multifunction Embedding Machine was purchased from Changzhou (China,
BM450A). LEICA Microtome was purchased from Leica (Germany, RM2235); Olympus microscope was purchased from Olympus (Japan, MPUSBX51). Mouse anti-galectin-1 monoclonal antibody (primary antibody) were purchased from Abcam (Cambridge, UK, 1:200). Mouse anti-CD34 monoclonal antibody (primary antibody) was purchased from Abcam (Cambridge, UK, 1:200). Horseradish peroxide 
enzyme-labeled anti-mouse/rabbit immunoglobulin polymer molecule (secondary antibody) was purchased from Dako (Denmark). 3,3-diaminobenzidine tetrahydrochloride was purchased from Dako (Denmark). Periodic acid solution (PAS) staining kit was purchased from Beijing Boaosen Biotechnology Co., Ltd. (China, S0127). Schiff reagent was purchased from Nanjing Big Bird Technology Co., Ltd. (China).

\section{Immunobistochemical staining}

All formalin-fixed and paraffin-embedded tissues were subjected to immunohistochemical staining. The paraffinembedded tissues were cut into $3 \mu \mathrm{m}$ thick sections. The sections were deparaffinized in xylene and rehydrated in gradient ethanol. Endogenous peroxidase was blocked with $3 \%$ hydrogen peroxide in methanol for 10 minutes. The slices were washed 3 times with phosphate buffer solution and pretreated with citrate buffer solution $(\mathrm{pH} 6.0)$ in a microwave oven at $95{ }^{\circ} \mathrm{C}$ for 20 minutes to perform antigen thermal retrieval. Anti-galectin-1 primary antibody (1:200; Abcam, Cambridge, UK) was added to the slides and incubated overnight at $4{ }^{\circ} \mathrm{C}$. Slides were rinsed with phosphate buffer for 3 minutes, then the slides were spun dry. The secondary antibody was added dropwise, and slides were incubated in a humidified atmosphere for 30 minutes. Slides were rinsed again with phosphate buffer for 3 minutes and dried, then DAB solution (1:50) was added for color development and incubated at room temperature for 10 minutes. The sections were washed and stained in hematoxylin for 5 minutes, and then washed under running water for 10 minutes. The sections were incubated in gradient alcohol and acetone, then coverslipped.

\section{CD34-PAS double staining}

CD34 was stained using immunohistochemical staining. The process was the same as described in the previous section. The PAS staining kit was used for PAS staining. After the DAB reaction, the sections were treated with $0.5 \%$ PAS for 10 minutes, and washed with distilled water 3 times for 3 minutes, then stained with the Schiff reagent at $4{ }^{\circ} \mathrm{C}$ in the dark for 20 minutes. The colored sections were washed thoroughly with water and stained with hematoxylin for 5 minutes, then washed again with water for 10 minutes. The sections were incubated in gradient alcohol and acetone, then coverslipped.

\section{Evaluation of IHC staining and CD34-PAS double staining}

Each specimen was subjected to immunohistochemical and CD34-PAS staining 3 times. The negative control (primary antibody omitted) was subjected to the same procedure. The reagent supplier provided a positive control. All slices were read by two senior pathologists using MPUS BX51 microscopes, and the diagnosis was completed independently. Galectin-1 staining was also scored according to the cell staining intensity: 0 points for unstained, 1 point for weak staining, 2 points for medium intensity staining, and 3 points for strong staining. Percentage scores of positive cells were also obtained according to the following criteria: 0 points for negative cells, 1 point for positive cells $<25 \%, 2$ points for $25-50 \%$, 3 points for $50-75 \%$, and 4 points for $>75 \%$. The product of the two scores was used as the final score of galectin-1 expression in rectal cancer tissue. Receiver operating characteristic (ROC) analysis was used to obtain the cutoff value of the galectin-1 immunohistochemical test score in rectal cancer tissue, so as to classify the test result as negative or positive.

The results of immunohistochemical double staining with CD34-PAS staining of 94 cases of rectal cancer tissues and corresponding adjacent tissues showed that VM was only found in rectal cancer tissues, and manifested as CD34-negative, PAS-stained duct-like structures, and the ducts contained red blood cells. Only endothelial cells with positive expression of CD34 and PAS were seen in the adjacent tissues, which depended on blood vessels, and no VM structures were seen.

\section{Data processing and statistical methods}

SPSS 16.0 (SPSS, Chicago, IL, USA) was used for statistical analysis of all data. The $t$-test was used to compare the two groups. The Kaplan-Meier method was used for survival analysis, and the survival rates of the two groups were compared using the log-rank test. ROC analysis was used to estimate the galectin-1 immunohistochemical test scores in rectal cancer tissues (Figure 1A). The Cox regression model was used to analyze the risk factors affecting the overall survival of patients with rectal cancer. $\mathrm{P}<0.05$ indicated that 


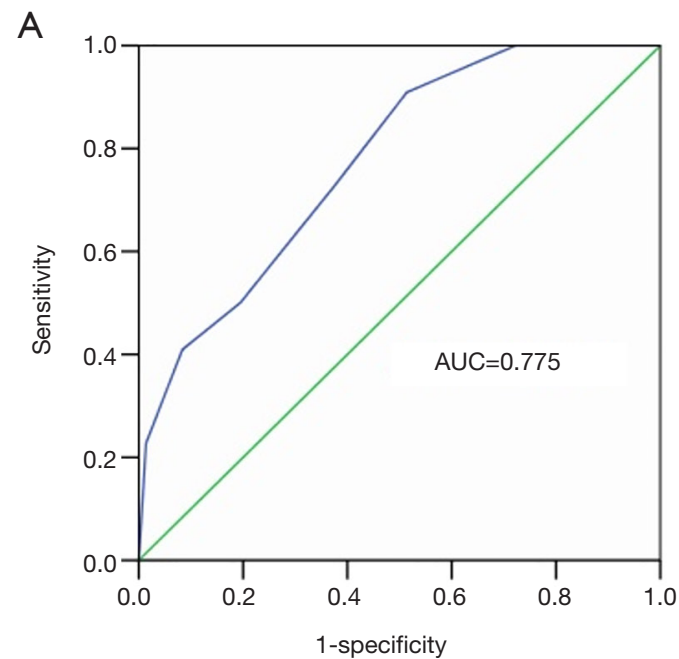

B
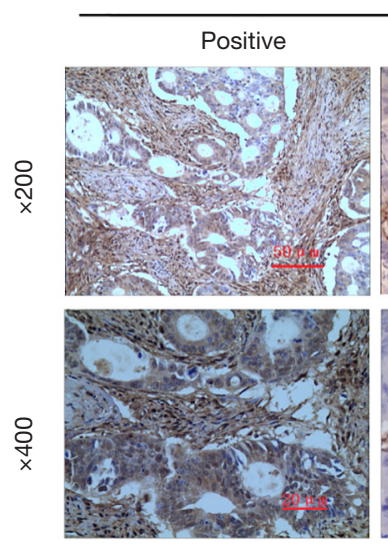

$\mathrm{RCT}$

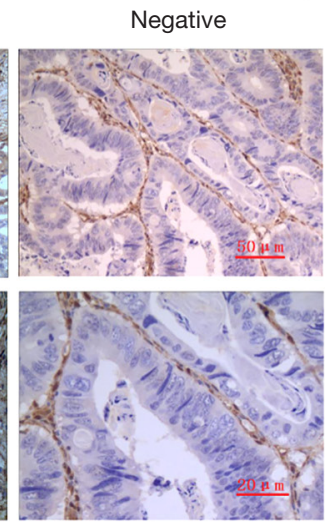

$\mathrm{NRCT}$

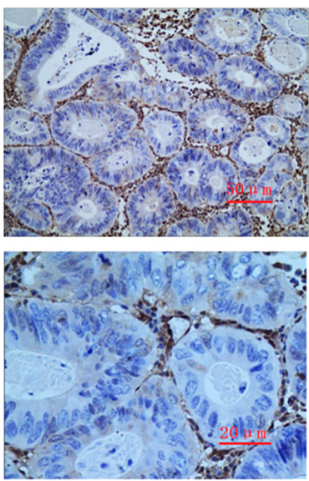

Figure 1 Immunohistochemical results of rectal cancer and adjacent normal tissues. (A) ROC curve of Galectin-1 with immunohistochemistry scores in rectal cancer tissue. (B) Galectin-1 expression in rectal cancer tissues and corresponding adjacent normal tissues (immunohistochemical staining). RCT, rectal cancer tissue; NRCT, negative rectal cancer tissue.

the difference was statistically significant.

\section{Results}

\section{Galectin-1 expression in rectal cancer tissues}

We performed immunohistochemistry on rectal cancer tissues and adjacent normal tissues (Figure 1B), and performed immunohistochemical scoring. ROC test results showed that the cutoff value of galectin-1 immunohistochemical scores in rectal cancer tissues was 5 (Figure 1A). According to the cutoff value, the statistical results showed that the positive expression rate of galectin-1 in 94 rectal cancer tissues was $45.7 \%$ (43 cases/94 cases).

\section{$V M$ formation status in rectal cancer tissues and corresponding adjacent tissue}

CD34-PAS immunohistochemical double staining results showed that VM structures were only found in rectal cancer tissues, and were not seen in the adjacent tissues. Furthermore, CD34-PAS immunohistochemical double staining showed that only CD34-positive endothelialdependent blood vessels were present in adjacent tissues (yellow arrow, Figure $2 A$ ), and that vascular endothelial cell-dependent blood vessels were visible in rectal cancer tissues (yellow arrow, Figure 2B), VM (green dashed line, Figure 2B), and red blood cells (red arrow, Figure 2B).

\section{The relationship between galectin-1 expression, VM, and various clinicopathological characteristics in rectal cancer tissues}

Among the 94 patients with rectal cancer, immunohistochemical staining showed that galectin-1 was expressed in 43 cases, and CD34-PAS double staining showed VM expression in 19 cases. According to the VM expression status, patients with rectal cancer were divided into the VM positive expression group and the VM negative expression group, and galectin-1 expression in rectal cancer tissues of the two groups was compared. The statistical results showed that galectin-1 expression in rectal cancer tissues of the VM positive expression group was significantly higher than the VM negative group, and the difference between the two groups was statistically significant $(\mathrm{P}<0.05)$. There was a significant correlation between the galectin-1 immunohistochemical score and VM structure formation in rectal cancer tissues $(\mathrm{r}=0.557, \mathrm{P}<0.001$; Figure 3), and VM structures were only found in rectal cancer tissues with positive expression of galectin-1. Analysis of the relationship between galectin-1, VM, and clinicopathological characteristics of rectal cancer patients showed that galectin-1 expression in primary rectal cancer tissues and VM were correlated with tumor differentiation, stage, lymph node metastasis, and tumor emboli in microvessels $(\mathrm{P}<0.05)$, but were not correlated with age, gender, tumor size, and tumor invasion depth ( $>>0.05$; Table 1). 

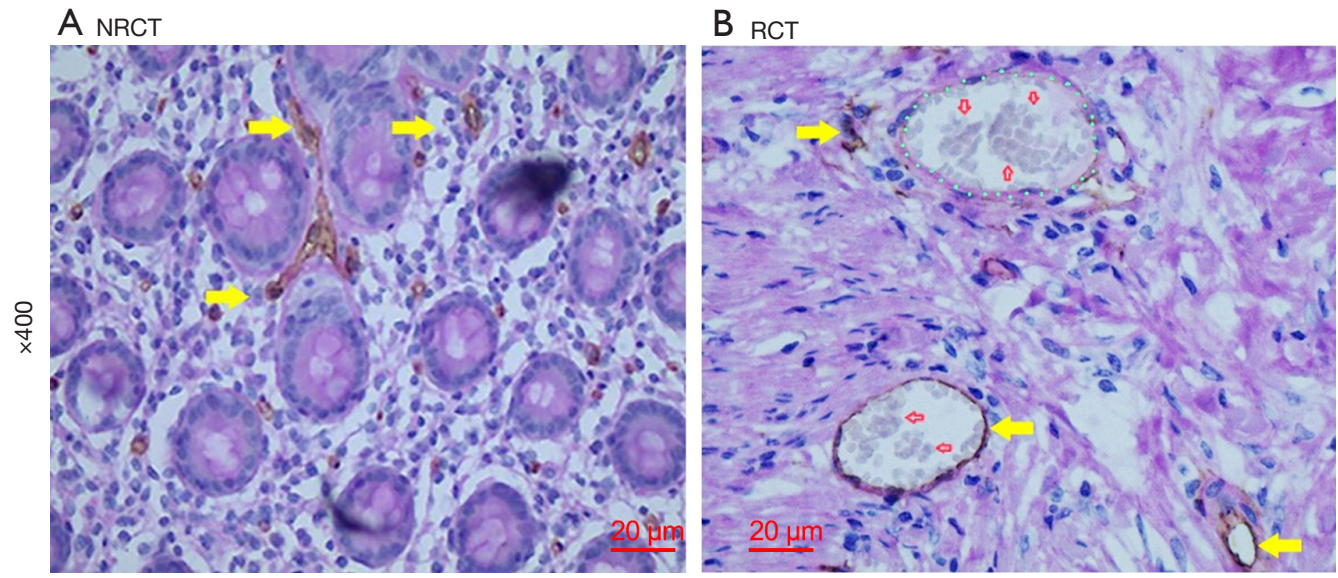

Figure 2 VM formation status in rectal cancer tissues and corresponding adjacent tissue. (A) A representative image of CD34-periodic acid solution (PAS) immunohistochemical double staining in rectal cancer tissue $(\times 400)$; (B) a representative image of CD34-PAS immunohistochemical double staining in adjacent tissue $(\times 400)$. Yellow arrows: endogenous cell-dependent vessels, VM (green dotted line); Red arrow: red blood cells. RCT, rectal cancer tissue; NRCT, negative rectal cancer tissue.

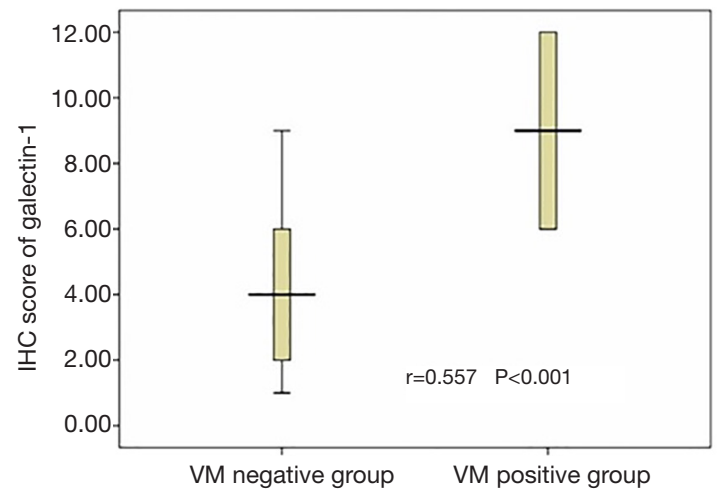

Figure 3 There was a significant correlation between galectin-1 immunohistochemical (IHC) scores and vascular mimicry (VM) structure formation $(\mathrm{r}=0.557, \mathrm{P}<0.001)$.

\section{The effect of galectin-1 expression and VM on rectal cancer prognosis}

The final follow-up date was December 31, 2019. KaplanMeier analysis showed that the OS time of rectal cancer patients in the galectin-1 positive expression group was $50.02 \pm 2.34$ months [95\% confidence interval (CI): 45.44-54.61], while the OS time of the galectin-1 negative expression group was $57.33 \pm 1.13$ months (95\% CI: 55.12 $59.55)$, and the difference between the two groups was statistically significant $(\mathrm{P}=0.003$, Figure $4 A)$. The OS time of rectal cancer patients in the $\mathrm{VM}$ positive expression group was $43.21 \pm 3.97$ months (95\% CI: $35.44-50.99$ ), while the
OS time of patients with rectal cancer in the VM negative expression group was $56.70 \pm 1.05$ months (95\% CI: 54.66 $58.79)$, and the difference between the two groups was statistically significant $(\mathrm{P}<0.001$, Figure $4 B)$. The OS time of the galectin-1 and VM negative expression group was $57.33 \pm 1.13$ months (95\% CI: 55.12-59.55), and the OS time of the galectin-1 and VM positive expression group was $43.21 \pm 3.97$ months (95\% CI: 35.44-50.99), while the OS time of the galectin-1 positive expression and VM negative expression group was $55.42 \pm 2.23$ months (95\% CI: $51.05-$ 59.78), and the difference between the galectin-1 and VM negative expression group, the galectin-1 and VM positive expression group and the galectin-1 positive expression and VM negative expression group was statistically significant $(\mathrm{P}<0.001$, Figure $4 C)$. Cox univariate regression analysis showed that differentiation, invasion, presence of tumor thrombus in the vessel, TNM staging, VM expression, and galectin-1 expression were the prognostic factors that affected the OS rate of patients. Multi-factor analysis results indicated that the depth of invasion of rectal cancer and the expression of VM were independent risk factors that affected the overall survival rate of patients (see Table 2).

\section{Discussion}

Galectin-1 was the first discovered member of the galectin family. It can form homodimers through noncovalent binding, which gives it the ability to cross-link specific glycogen binders. In cells, galectin-1 is involved 

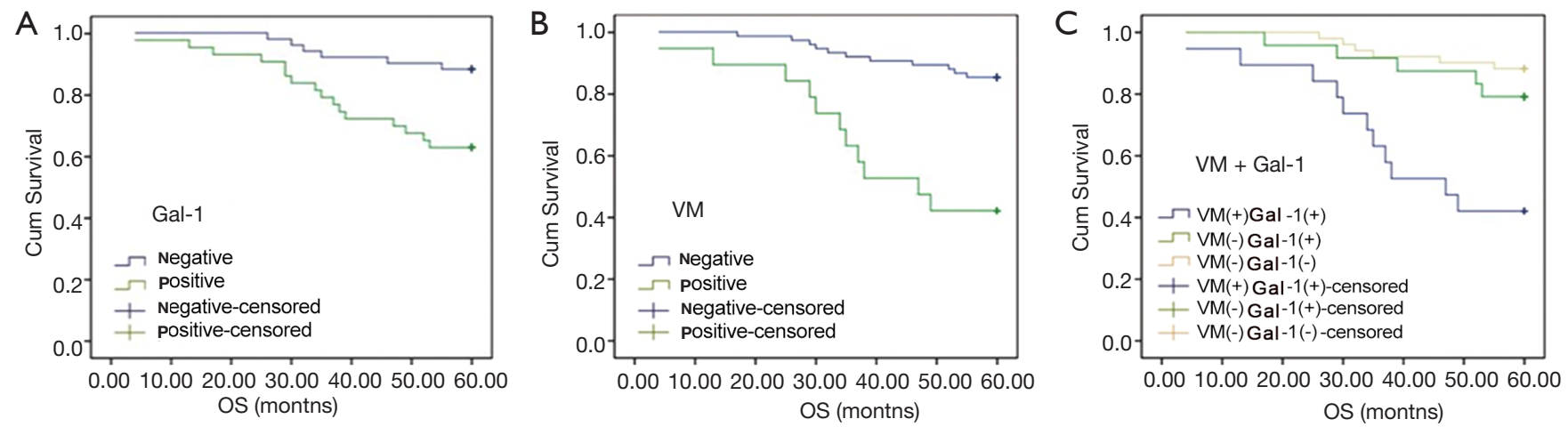

Figure 4 The effect of galectin-1 expression and vascular mimicry (VM) formation in rectal cancer tissue samples on patient overall survival (OS). (A) The effect of galectin-1 expression in rectal cancer tissue samples on patient OS; (B) the effect of VM formation in rectal cancer tissue samples on patient OS; (C) combined detection of the effects of galectin-1 and VM expression in rectal cancer tissue samples on patient OS.

Table 2 Cox regression analysis of factors affecting the prognosis of patients with rectal cancer

\begin{tabular}{lccc}
\hline \multirow{2}{*}{ Variable } & \multicolumn{1}{c}{ Single-factor analysis } & \multicolumn{1}{c}{ Multi-factor analysis } \\
\cline { 2 - 3 } & $\mathrm{HR}(95 \% \mathrm{Cl})$ & $\mathrm{HR}(95 \% \mathrm{Cl})$ & - \\
\hline Gender (female vs. male) & $0.50(0.20-1.22)$ & 0.127 & - \\
Age (>60 vs. $<60$ years old) & $1.13(0.46-2.77)$ & 0.07 & - \\
Tumor size (>5 vs. $<5 \mathrm{~cm})$ & $1.29(0.55-3.03)$ & 0.553 & - \\
Degree of differentiation & $0.27(0.12-0.59)$ & 0.001 & - \\
(high vs. medium vs. poor) & & & - \\
Tumor invasion depth (T4 vs. T1-3) & $3.95(1.61-9.70)$ & 0.003 & - \\
Lymph node metastasis (positive vs. negative) & $2.04(0.88-4.70)$ & 0.096 & - \\
Intravascular tumor thrombus (positive vs. & $2.56(1.11-5.93)$ & 0.028 & - \\
negative) & & & - \\
Clinical stage (III vs. II vs. I) & $2.38(1.19-4.76)$ & 0.014 & - \\
VM (positive vs. negative) & $5.53(2.39-12.82)$ & $<0.001$ & - \\
Gal-1 (positive vs. negative) & $2.45(1.03-5.84)$ & 0.044 & 0.001 \\
\hline
\end{tabular}

$\mathrm{HR}$, hazard ratio; Cl, confidence interval; VM, vascular mimicry; Gal-1, galectin-1.

in the pre-splicing of mRNA. It interacts with oncogenic $\mathrm{H}-\mathrm{R}$ as and promotes cell migration, demonstrating its key role in driving tumor transforming proteins to affect tumor progression, invasion, and angiogenesis $(12,13)$. A large number of studies have suggested that galectin-1 is amplified and highly expressed in thyroid cancer, head and neck cancer, gastric cancer, colon cancer, ovarian cancer, and prostate cancer (14-16), and the high expression of galectin-1 is correlated with poor prognosis (17-19). However, few studies have evaluated the relationship between galectin-1 expression and the survival rate of patients with rectal cancer. In this study, we used immunohistochemistry to detect the expression of galectin-1 in 94 rectal cancer tissue samples, and found that 43 of the 94 rectal cancer samples were positive for galectin-1 (45.7\%). The expression of galectin-1 was correlated with the degree of differentiation, stage, lymph node metastasis, and intravascular tumor emboli. KaplanMeier survival analysis confirmed that the overall survival rate of the galectin-1 positive expression group was 
significantly lower than that of the negative expression group. Therefore, detecting the expression of galectin-1 in rectal cancer tissues may help to evaluate the prognosis of rectal cancer patients, and provide clinical indicators for the selection of comprehensive treatment for rectal cancer patients.

VM is found in many solid tumors, and the formation of VM structures also indicates poor prognosis $(5,8)$. VM provides necessary nutrients for tumors and promotes tumor growth. Because the VM structure lacks endothelial cells, it is only a tube-like structure surrounded by mucopolysaccharide components, which is beneficial for tumor cells to invade. In addition, VM is connected with endothelium-dependent blood vessels, which is an important way for tumor cells to enter blood circulation (7). However, the impact of VM on the prognosis of patients with rectal cancer is still controversial $(20,21)$. Previous studies have shown that VM structure formation is not closely related to the prognosis of patients with rectal cancer (22). In this study, we performed CD34-PAS immunohistochemical double staining of 94 rectal cancer samples and found that 19 (20.2\%) were VM positive. Our research results showed that VM structure formation was closely correlated with clinically poor prognostic factors such as tumor differentiation, tumor clinical stage, lymph node metastasis, and intravascular tumor thrombus. KaplanMeier survival analysis also confirmed that the overall survival rate of patients in the VM positive group was significantly lower than that in the VM negative group, and the Cox multi-factor regression analysis showed that VM structure formation was an independent factor affecting the prognosis of patients with rectal cancer.

So far, the molecular mechanism of VM generation is not fully understood. Our research found that VM structure formation in rectal cancer tissue was significantly correlated with the expression of galectin-1, and galectin-1 and VM were also correlated with the clinicopathological characteristics of rectal cancer, which suggests that there is a certain connection between them. It is speculated that the high expression of galectin-1 may be an important regulatory factor for promoting VM production. The positive expression of galectin-1 and VM in rectal cancer tissue is indicative of poor prognosis in patients with rectal cancer. The detection of galectin-1 and VM expression in rectal cancer tissue may therefore become a new important indicator for evaluating postoperative prognosis and guiding the clinical treatment of patients with rectal cancer. In addition, galectin-1 and VM are expected to become novel targets for the targeted therapy of rectal cancer.

\section{Acknowledgments}

Funding: None.

\section{Footnote}

Reporting Checklist: The authors have completed the REMARK reporting checklist. Available at http://dx.doi. org/10.21037/tcr-21-121

Data Sharing Statement: Available at http://dx.doi. org/10.21037/tcr-21-121

Conflicts of Interest: All authors have completed the ICMJE uniform disclosure form (available at http://dx.doi. org/10.21037/tcr-21-121). The authors have no conflicts of interest to declare.

Ethical Statement: The authors are accountable for all aspects of the work in ensuring that questions related to the accuracy or integrity of any part of the work are appropriately investigated and resolved. The study was conducted in accordance with the Declaration of Helsinki (as revised in 2013). The study was approved by Affiliated Hospital of Medical College of Yangzhou University (No. TZRY-EC-18-012). All subjects were informed and signed the informed consent.

Open Access Statement: This is an Open Access article distributed in accordance with the Creative Commons Attribution-NonCommercial-NoDerivs 4.0 International License (CC BY-NC-ND 4.0), which permits the noncommercial replication and distribution of the article with the strict proviso that no changes or edits are made and the original work is properly cited (including links to both the formal publication through the relevant DOI and the license). See: https://creativecommons.org/licenses/by-nc-nd/4.0/.

\section{References}

1. Ma ZH, Wang YP, Zheng WH, et al. Prognostic factors and therapeutic effects of different treatment modalities for colorectal cancer liver metastases. World J Gastrointest Oncol 2020;12:1177-94 .

2. Mawalla B, Yuan XL, Luo XX, et al. Treatment outcome of anti-angiogenesis through VEGF-pathway in the 
management of gastric cancer: a systematic review of phase II and III clinical trials. BMC Res Notes 2018;11:21.

3. Maniotis AJ, Folberg R, Hess A, et al. Vascular channel formation by human melanoma cells in vivo and in vitro: vasculogenic mimicry. Am J Pathol 1999;155:739-52.

4. Le X, Sun B, Guo S, et al. Current status and prospects of angiogenic mimicry in tumor research. Modern Oncology Medicine 2014;(9):2204-7, 2208.

5. You X, Wang $\mathrm{Y}, \mathrm{Wu} \mathrm{J}$, et al. Prognostic significance of galectin-1 and vasculogenic mimicry in patients with gastric cancer. Onco Targets Ther 2018;11:3237-44.

6. Qiao L, Liang N, Zhang JD, et al. Advanced research on vasculogenic mimicry in cancer. J Cell Mol Med 2015;19:315-26.

7. Han C, Sun B, Zhao X, et al. Phosphorylation of STAT3 promotes vasculogenic mimicry by inducing epithelialto-mesenchymal transition in colorectal cancer. Technol Cancer Res Treat 2017;16:1209-19.

8. López-Camarillo C, Ruiz-García E, Starling N, et al. Editorial: Neovascularization, Angiogenesis and Vasculogenic Mimicry in Cancer. Front Oncol 2020;10:1140.

9. Yang RY, Rabinovich GA, Liu ET. Galectins: structure, function and therapeutic Potential. Expert Rev Mol Med 2008;10:e17.

10. Li F, He X, Fu Q, et al. Expression of Galectin-1 in gastric cancer tissues and its role in gastric cancer angiogenesis. Shandong Medicine 2010;50:15-7.

11. Park GB, Kim D. TLR4-mediated galectin-1 production triggers epithelial-mesenchymal transition in colon cancer cells through ADAM10- and ADAM17-associated lactate production. Mol Cell Biochem 2017;425:191-202.

12. Wu B, Liu N, Ai Q, et al. Galectin-1 and its role in tumor development. Journal of Yan'an University (Medical Science Edition) 2017;15:80-2, 85 .

Cite this article as: Zhou H, Zhang D, Yang M, You X, Zhang Q, Fu X, Wang D. The predictive value of galectin-1 and vascular mimicry in the prognostic evaluation of patients with rectal cancer. Transl Cancer Res 2021;10(3):1500-1508. doi: $10.21037 /$ tcr-21-121
13. Barondes SH, Castronovo V, Cooper DN, et al. Galectins: a family of animal beta-galactoside-binding lectins. Cell 1994;76:597-8.

14. Cousin JM, Cloninger MJ. The role of galectin-1 in cancer progression, and synthetic multivalent systems for the study of galectin-1. Int J Mol Sci 2016;17:1566.

15. You X, Wang Y, Wu J, et al. Galectin-1 Promotes Metastasis in Gastric Cancer Through a Sphingosine1-Phosphate Receptor 1-Dependent Mechanism. Cell Physiol Biochem 2018;51:11-30.

16. Chong Y, Tang D, Gao J, et al. Galectin-1 induces invasion and the epithelial-mesenchymal transition in human gastric cancer cells via non- canonical activation of the hedgehog signaling pathway. Oncotarget 2016;7:83611-26.

17. Chen L, Yao Y, Sun L, et al. Clinical implication of the serum galectin-1 expression in epithelial ovarian cancer patients. J Ovarian Res 2015;8:78.

18. Su YC, Davuluri GV, Chen CH, et al. Galectin-1-induced autophagy facilitates cisplatin resistance of hepatocellular carcinoma. PLoS One 2016;11:e0148408.

19. Wang W, Zhou Z, Xiang L, et al. CHIP-mediated ubiquitination of Galectin-1 predicts colorectal cancer prognosis. Int J Biol Sci 2020;16:719-29.

20. Yang $\mathrm{Y}, \mathrm{Hu} \mathrm{Y,Wu} \mathrm{N}$, et al. Research progress of tumor angiogenesis mimicry in colon cancer. Modern Oncology Medicine 2018;26:149-52.

21. Gu R, Ma X, Wang L. Research progress in the evaluation of the efficacy of anti-angiogenic drugs for advanced colorectal cancer. J Clin Oncol 2019;24:81-6.

22. Cao Z, Bao M, Miele L, et al. Tumour vasculogenic mimicry is associated with poor prognosis of human cancer patients: a systemic review and meta-analysis. Eur J Cancer 2013;49:3914-23.

(English Language Editor: C. Betlazar-Maseh) 